Research Article

\title{
A comparative study of the antibiotic utilization during the normal and caesarean section deliveries at Jawaharlal Nehru institute of medical sciences hospital, Imphal, Manipur, India
}

\author{
Joychandra Singh Oinam, Debashree Ningthoujam*, Indira Raleng
}

Department of Pharmacology, JNIMS, Imphal, Manipur, India

Received: 25 February 2016

Revised: 29 February 2016

Accepted: 08 April 2016

*Correspondence to:

Dr. Debashree Ningthoujam, Email: debashree27@gmail.com

Copyright: (C) the author(s), publisher and licensee Medip Academy. This is an openaccess article distributed under the terms of the Creative Commons Attribution NonCommercial License, which permits unrestricted noncommercial use, distribution, and reproduction in any medium, provided the original work is properly cited.

\begin{abstract}
Background: $\mathrm{C}$ section delivery is increasing with non-medical reasons with use of more antibiotics and long hospital stay.

Methods: The study is a record based retrospective study of the Bed Head Tickets of the discharged patients of $\mathrm{C}$-section and normal deliveries for the duration of 94 days. Census method of sampling of data was followed. Data particularly drug utilisation pattern of the prescribed drugs like dosage form, route, frequency of administration and duration of delivery from those BHTs and discharge slip were collected in a predesigned and pretested proforma.

Results: The Normal delivery is less expensive with less use of antibiotics and short hospital stay and easy recovery to normal health.

Conclusions: Pregnancy is just a natural process (not a disease or a medical condition) and external intervention should occur only for sound medical conditions $\mathrm{C}$ section delivery cannot replace normal delivery in terms of low maternal mortality and neonatal morbidity and less cost. Prescribing antibiotics to mother of normal delivery may also be avoided if the complete sterilization process during and after the delivery is assured.
\end{abstract}

Keywords: Caesarean section delivery, Normal vaginal delivery, Antibiotics, BHT

\section{INTRODUCTION}

Women consider vaginal delivery as an integral part of being a woman and becoming a mother. But baby delivered with caesarean section operation is regarded as a God's gift to the modern woman.

Drug utilization study is a structural process used to assess the quality of drug therapy by engaging in the evaluation of data on drug prescribing, dispensing and/or patient use in a given healthcare environment against predetermined agreed upon criteria and standard. ${ }^{2}$ It emphasizes rational, economical, authentic, proper, adequate and appropriate use of drugs. There are several studies with drug utilization pattern of different drugs for different disease conditions.,

\section{METHODS}

Preparatory ground work of this record based retrospective study was done in the department of pharmacology (JNIMS). Permission for handling the records was obtained from the medical superintendent and MRO of JNIMS. Hospital study materials were bed head tickets (BHTs) of the discharged patients who underwent the C.S. operation and normal deliveries. These were available in the medical record section of the JNIMS. Screening of records for the months of June, July, August 2015 was done in the medical record section for the BHTs and discharge slip. ${ }^{3}$ As per the customary law and tradition the maximum number of marriage ceremony was performed w.e.f. September and continued up to June of every year for the large population 
particularly the meitei community in Imphal city and area around JNIMS hospital. Therefore there is maximum number of delivery during June, July and August.

Census method of sampling of data was followed. Data particularly drug utilisation pattern of the prescribed drugs like dosage form, route, frequency of administration and duration of delivery from those BHTs and discharge slip were collected in a predesigned and pretestedproforma. ${ }^{3}$ The whole exercise was completed in two months ie October and November 2015. The collected data was compiled, audited and analysed statistically by calculating percentage, proportions, etc. ${ }^{3}$

Rationality in respect of drug prescription and therapeutic indication was also evaluated; The cost effectiveness of the prescription was also examined by referring the price list of the Ref Rx (July-October 2012) published by Refrx Mediatech Pvt Ltd Bengaluru. ${ }^{5,11}$

\section{RESULTS}

The period of study is 94 days (13/15/2015 to $18 / 8 / 2015)$. The case sheets which were provided for scrutiny during the above mentioned period is 200 cases as per the record of the medical record office (JNIMS hospital). The record was again confirmed from the record of the nursing superintendent of the obstetrics and gynaecology department. The number of women who delivered babies by caesarean section and the duration of hospital stay are also examined. The age of women is between 25-45 years and they are mostly prime delivery. The socioeconomic and educational statuses of the women are mainly middle class. They are presented as below.

Table 1: Caesarean number of caesarean deliveries and days of hospital stay.

\begin{tabular}{|c|c|c|c|}
\hline No. of deliveries & Days o & jital stay & Remarks \\
\hline 65 & 3 days & \multirow{5}{*}{\multicolumn{2}{|c|}{$\begin{array}{l}\text { On average- No. of } \\
\text { deliveries } 2.12 \text { cases } \\
\text { per day or } 15 \text { cases per } \\
\text { weeks } \\
\text { No. of days at hospital - } \\
5 \text { days (approx.) }\end{array}$}} \\
\hline 88 & 4 days & & \\
\hline 37 & 5 days & & \\
\hline 8 & 6 days & & \\
\hline 2 & 7 days & & \\
\hline
\end{tabular}

The antibiotics were given on the day of CS operation and the same were continued up to one day before going home. Thereafter the preparation of antibiotic was change to oral preparations or discontinues as such. Usually the patient's party requested the doctor to discharge on $4^{\text {th }}$ and $5^{\text {th }}$ days after delivery as there was ritual ceremony (swasti puja) of the birth of the babies are usually done on $6^{\text {th }}$ day after delivery. The name of antibiotic single or combination along with route of administration dosage schedule is given below.

Similarly the number of normal vaginal delivery during the above mentioned duration (13/5/2015-18/8/2015) is 20 only. The age of the women is $30-50$ years, they are mostly multipara and low socioeconomic group and few are illiterate, the number of women who delivered babies normally and the number of day at hospital is given below.

Table 2: Antibiotic used (CS delivery).

\begin{tabular}{|llll|}
\hline Name of antibiotic & Case/ route of administration & Single/combination & Approx. expenditure \\
\hline Amikacin & 31, iv (BD) & Single & Rs. 600 for 5 days @ Rs. 60/vial \\
\hline Ceftriaxone sulbactam & 99, iv (BD) & combination & Rs. 1400 for 5 days @ 140/vial \\
\hline Ceftriaxone+Tazobactam & 65, iv (BD) & combination & Rs. 1380 for 5 years @ 138/ vial \\
\hline Piperacillin+Tazobactam & 6, iv (BD) & combination & Rs. 1500 for 5 years @ Rs. 150/vial \\
\hline
\end{tabular}

Table 3: Normal number of normal deliveries and days of hospital stay.

\begin{tabular}{|lll|}
\hline Number of patients & \multicolumn{1}{c|}{ Duration } & \multicolumn{1}{c|}{ Remarks } \\
\hline 11 & 1 days & On average no. of days at hospital-2 days. no. of \\
& delivery 1.4 case per weeks (approx.)
\end{tabular}

Table 4: Antibiotic used (normal delivery).

\begin{tabular}{|lclll|}
\hline Name of antibiotic & Number of patients & Route & \multicolumn{2}{l|}{ Single/combination Approx. expenditure } \\
\hline Ceftriaxone+sulbactam & 18 & Iv (BD) & Combination" & Rs. 560 for 2 day@ Rs.140/vial \\
\hline Ceftriaxone+Tazobactam & 2 & Iv (BD) & Combination" & Rs. 552 for 2 days@ Rs138 /vial \\
\hline Amikacin & - & - & - & -
\end{tabular}

The antibiotics were given on the day of delivery. The same was continued as oral preparations as the women were usually discharged next day of the delivery. Single component drug was not given. The combination product 
was more effective. The name of the drug single/combination drug, route of administration and dosage schedule is given.

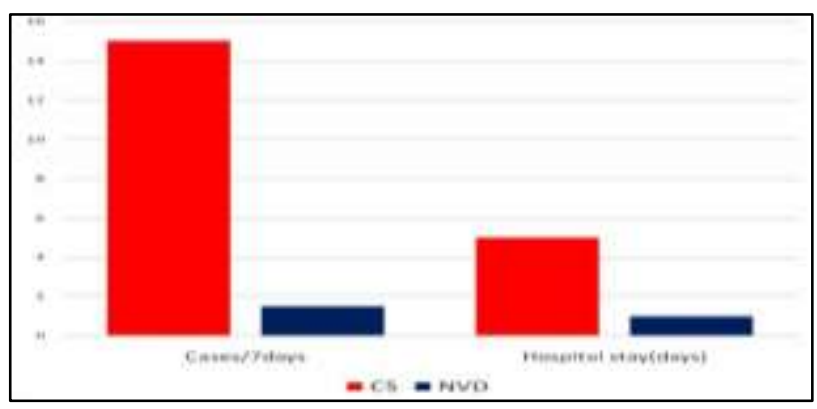

Table 1: The number of delivery and hospital stay.

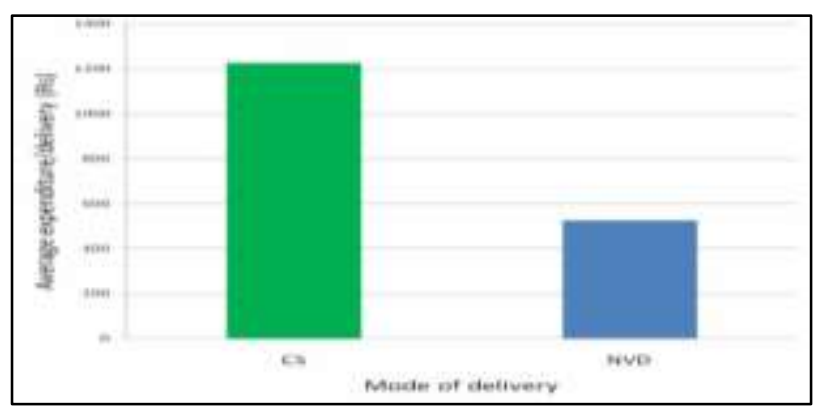

Table 2: The mode of delivery and average expenditure per delivery.

\section{DISCUSSION}

C-section is considered fashionable and overlooking the fact that such a major surgery probably does not belong in the real in purely suomotu decision. ${ }^{1}$ When the C-section is done for genuine medical reasons, a $\mathrm{C}$-section is saving two lives in one go and also one of the safest and most effective operation. ${ }^{1}$ But the number of $\mathrm{C}$-section is increased for non-medical reasons like good time, favourable day, painless delivery, cash or kind for conducting the operation to the health provider. ${ }^{6}$ It carries potential complications in regards of anaesthetic drugs and anaesthetic process and surgical process and nursing care etc for both mother and baby than the uncomplicated normal birth. ${ }^{7}$ Considering merit and demerit of $\mathrm{C}$ section-on the criteria mentioned above-drug utilizationparticularly during hospital stay, expenditure on hospital stay, transport, attendance, nursing etc. C-section is not desirable. ${ }^{7,8,9}$ But accounting those criteria mentioned above again, the number of delivery by $\mathrm{C}$-section is. ${ }^{2} 15$ cases per day ie 15 cases per week. Whereas the number of delivery by normal birth is about 1.4 case per weeks. The number of days at hospital and expenditure for antibiotics for C-section is 3-7 days (average 5 days) and Rs. 600-Rs. 1500 (average Rs. 1220). Whereas for normal birth is 1-3 days (average 2 days) and Rs. 552-Rs. 600 (average Rs. 576). Respectively the mothers along with babies want to attend the ritual ceremony (swasti puja) on $6^{\text {th }}$ day after delivery. Many a time the mothers miss the ceremony or the ceremony may be postponed. But the mother and baby in case of normal delivery is always able to attend the ceremony on $6^{\text {th }}$ day after delivery

On the comparative study, C-section delivery is more expensive due to malpractice, time consuming process and recovery also take time to normal health, risk factors and complications of $\mathrm{C}$-section deliveries are always counted for mother and baby. ${ }^{10}$

Normal vaginal delivery is less expensive, short hospital stay, quick recovery to normal health and can attend swasti puja in time.

\section{CONCLUSION}

Pregnancy is just a natural process (not a disease or a medical condition) and external intervention should occur only for sound medical conditions $\mathrm{C}$ section delivery cannot replace normal delivery in terms of low maternal mortality and neonatal morbidity and less cost. Prescribing antibiotics to mother of normal delivery may also be avoided if the complete sterilization process during and after the delivery is assured

\section{ACKNOWLEDGEMENT}

The authors thank the medical superintendent and the MRO of JNIMS Hospital for allowing studying the BHTs of the CS delivery and normal vaginal delivery for the duration i.e June, July August 2015.

\section{Funding: No funding sources}

Conflict of interest: None declared

Ethical approval: The study was approved by the Institutional Ethics Committee

\section{REFERENCES}

1. Kumbhar K. This caesarean Epidemic, Let's marke normal deliveries the normal again; 2016.

2. WHO introduction of drug utilization research generva-WHO; 2003:6-48.

3. Biswas S, Kumar K, Holder MS. Pharmaco epidemiology of drug utilized for cataract surgery in a Govt. medical college and Hospital JIMA. 2010;108(12):829-32.

4. Mohanty M, Mohapatra S. Drug utilization pattern of topical ocular antimicrobials in a tertiary care Hospital; Indian J. Pharmacology. 2003;35:399.

5. Ref Rx (July-October 2012) published by Refrx Mediatech pvt.Ltd. Bengalaru.

6. Kushtagi P, Guruvares. Documenting indication of caesarean deliveries postgraduate Med. J. 2008;54(1):52-3.

7. Mishra US, Ramanathan M. Delivery related complications and determinants of caesarean section rates in India: health policy plan. 2002:17(1):90-8.

8. Lius, Liston RM, Joseph KS, Heaman M, Sauve R, Kramer MS. Maternal mortality and severe morbidity 
associated with low risk planned case delivery at term, maternal health study group the cannadian perinatal surveillance system.

CMAJ. 2007;176(4):45560.

9. Clark SL, Belfort MA, Dildy GA, Herbst MA Maternal deaths in the $21^{\text {st }}$ century, causes, prevention and relationship to caesarean delivery Am J. obstetric gynecol. 2008;199(1):36.
10. Git A. Caesarean section evaluation, guidelines and recommendations Indian $\mathbf{J}$ Med ethics. 2008;5(3):117-20.

11. PAI M. Unnecessary medical interventions, caesarean section as a case study economic and political weekly. 2000;305(31):2755-61.

Cite this article as: Oinam JS, Ningthoujam D, Raleng I. A comparative study of the antibiotic utilization during the normal and caesarean section deliveries at Jawaharlal Nehru institute of medical sciences hospital, Imphal, Manipur, India. Int J Basic Clin Pharmacol 2016;5:794-7. 